\title{
Direitos Sexuais, Direitos Reprodutivos: concepções de mulheres negras e brancas sobre liberdade'
}

\section{Sexual and Reproductive Rights: the conceptions of black and white women regarding freedom'}

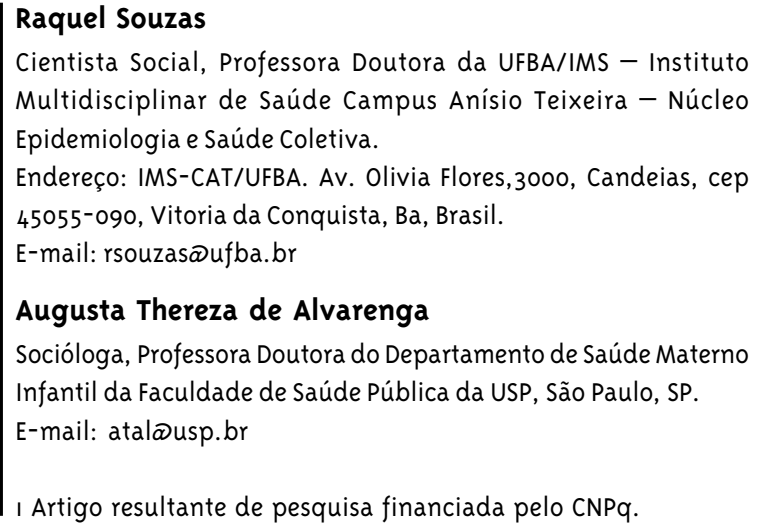

Cientista Social, Professora Doutora da UFBA/IMS - Instituto Multidisciplinar de Saúde Campus Anísio Teixeira - Núcleo Epidemiologia e Saúde Coletiva.

Endereço: IMS-CAT/UFBA. Av. Olivia Flores, 3000 , Candeias, cep 45055-090, Vitoria da Conquista, Ba, Brasil.

E-mail: rsouzasळufba.br

\section{Augusta Thereza de Alvarenga}

Socióloga, Professora Doutora do Departamento de Saúde Materno Infantil da Faculdade de Saúde Pública da USP, São Paulo, SP.

E-mail: atalœusp.br

I Artigo resultante de pesquisa financiada pelo CNPq.

\section{Resumo}

A saúde reprodutiva relaciona-se ao usufruto da liberdade intrínseca aos direitos sexuais e reprodutivos. A questão central, neste artigo, é como a noção de liberdade se articula à condição social, de gênero, raça/ etnia, com o intuito de investigar diferenças de gênero e de raça nas questões reprodutivas de mulheres negras e brancas, em relação à concepção de liberdade. A pesquisa é de natureza qualitativa e aborda questões reprodutivas de mulheres, a partir de um recorte de gênero e raça. Foram entrevistadas 36 mulheres, autoclassificadas brancas e negras (pretas e pardas), em união conjugal há, pelo menos, um ano. Os discursos foram analisados articulando-se raça/etnia e diferentes níveis de escolaridade. No conjunto, observa-se que as condições de vida e saúde reprodutiva de mulheres negras e brancas diferenciam-se em razão das condições socioeconômicas e culturais. Comparativamente, os discursos dos dois grupos podem ser interpretados em dois níveis característicos, da vida privada e do espaço público: enquanto mulheres brancas focam a defasagem das mulheres, no exercício eqüitativo da liberdade em relação aos homens, mas destacam conquistas no mundo do trabalho, mulheres negras pensam a liberdade mais circunscrita à possibilidade de vivência democrática da conjugalidade. As diferenças de discurso em relação à liberdade podem estar relacionadas tanto à questão do racismo no Brasil, historicamente vivenciado por mulheres negras no cotidiano, como às questões especificamente culturais dos dois grupos estudados.

Palavras-chave: Liberdade; Gênero; Raça/Etnia; Direitos sexuais e reprodutivos. 


\section{Abstract}

Reproductive health is related to the enjoyment of freedom that is intrinsic to sexual and reproductive rights. The core issue, in this article, is how the notion of freedom articulates itself to the social condition of gender, race and ethnicity. To investigate gender and race differences in reproductive issues of black and white women regarding the conception of freedom. The research is of a qualitative nature and approaches reproductive issues of women based on an outline of gender and race. Thirty-six women were interviewed, self-classified as white and black (black and mulatto), in conjugal union for, at least, one year. The discourses were analyzed articulating race/ethnicity and different levels of schooling. Overall, one can observe that the life conditions and reproductive health of black and white women differ due to socio-economic and cultural conditions. Comparatively, the discourses of the two groups can be interpreted in two characteristic levels, those of private life and public space: while white women focus on the delay of women in the equitable exercise of freedom compared to men, but highlight achievements in the world of labor, black women view freedom as concerning the possibility of a democratic experience of conjugality. The differences in discourses as to freedom can be related as much to the issue of racism in Brazil suffered daily by black women throughout history, as to the specifically cultural issues of the two groups that were studied.

Keywords: Freedom; Gender; Race/Ethnicity; Sexual and Reproductive Rights.

\section{Introdução}

Direitos sexuais e reprodutivos são construções recentes, frutos de reflexões teóricas sobre os direitos individuais e coletivos. É dentro da concepção dos Direitos Humanos que eles se constituem nos espaços públicos e privados. Há, certamente, na concepção moderna desses direitos, a idéia de uma intimidade democratizada pelos avanços políticos na vida pública, como concebeu Giddens (1993). Uma concepção fundamental, veiculada por esses direitos, é a autonomia, que requer o direito fundamental do exercício da liberdade.

$\mathrm{Na}$ análise de Giddens (1991), a vida moderna eliminou a fronteira entre o "nós" e os "outros" e os riscos que poderiam estar no mundo dos "outros" fazem parte do nosso mundo, porém distribuídos desigualmente, re-hierarquizados.

A autonomia moral dos indivíduos, diante dessa modernidade, depende muito das condições sociais, culturais e institucionais para o seu desenvolvimento, e a cidadania pressupõe o usufruto da liberdade e da responsabilidade (Venturi Jr., 2003).

Segundo Giddens (1993), a intimidade está sendo cada vez mais democratizada, em um movimento de fora para dentro, do campo da vida privada. Esse processo de democratização, alavancado pela revolução feminista no cotidiano, possibilitou a constituição de sujeitos políticos para o exercício da cidadania. Para Rodrigues (2001, p.238), "O exercício de cidadania compreende duas ações interdependentes, a primeira refere-se à participação lúcida dos indivíduos em todos os aspectos da organização e da condução da vida privada e coletiva; e a segunda diz respeito à capacidade que esses indivíduos adquirem para operar escolhas".

A emancipação feminina, em busca do direito à escolha, já deu largos passos em direção à autonomia. O casamento por muito tempo foi a única forma de as mulheres obterem uma identidade social, e o contrato matrimonial, datado na origem do patriarcalismo, tem como base a dominação e sujeição da mulher ao homem. Equiparada ao escravo, em face desse contrato matrimonial e sexual, a mulher, historicamente, não exercia o mesmo direito que o homem, direito esse alocado no "individuo" e referido à masculinidade. Ligado ao patriarcado, o contrato matrimonial e sexual não permitia a igualdade à feminilidade, e a liberdade de fazer acordos e contratos se referia às pessoas com 
direito político, o que era negado à mulher e referido aos homens (Pateman, 1993). A liberdade dos "indivíduos", mencionada no 'contrato social' em Hobbes, Locke e Rousseau, segundo Pateman (1993), não alcançava as mulheres, porque elas estavam no lugar do "não-sujeito". Mulheres negras têm se firmado como sujeito social e político, de forma que a história tem se transformado, como podemos constatar através de inúmeros documentos, veiculados em diferentes fontes, que comprovam a crescente organização social e política das mulheres negras.

A questão da diferença, nesse debate, é colocada, com a intenção de problematizar valores e normas sociais impostas por uma dada moralidade. A mulher negra, posta duplamente no lugar de "não sujeito", estabelece uma diferença na diferença. Sob a égide do diferencialismo, em oposição ao igualitarismo, instaura-se um dilema ou, mais propriamente, uma "cilada", como aponta Pierucci (200o). Pensa-se sobre esta questão que, ao ampliar o horizonte e as identidades, possibilita um alcance maior de justiça e de autonomia. Trata-se de "pluralizar" os negócios humanos, como assinala Arendt (apud Telles, 1999). Como refere Oliveira (1991), a mulher passou da luta pela igualdade para a luta pelo direito à diferença, sem prejuízo para a convicção pela igualdade de direitos.

Pensar a liberdade, nesse sentido, é fundamental para a avaliação dos processos de decisão e escolhas reprodutivas, historicamente, um campo em que se refletem a dominação e sujeição de mulheres negras e brancas. No que se refere à cidadania, tal questão é crucial, em um sentido amplo. Daí, nosso interesse em reter, a partir do discurso de mulheres negras e brancas, a concepção de liberdade, que se faz presente nas falas de mulheres negras e brancas entrevistadas.

\section{Metodologia}

Este trabalho foi produzido a partir de pesquisa, desenvolvida e apresentada como tese de doutorado (Souzas, 2004). Trata-se de pesquisa de natureza qualitativa, que abordou temáticas acerca das questões reprodutivas de mulheres negras e brancas, a partir de um recorte de gênero e raça, no campo da Saúde Pública. Foram entrevistadas 36 mulheres, sendo 18 negras (pretas e pardas) e 18 brancas, a partir do critério de autoclassificação, todas vivendo em união conjugal há, pelo menos, um ano. Foram selecionadas mulheres com idade de 25 a 49 anos. Para essa seleção, foi utilizada a técnica da "bola de neve", que consistiu na criação de uma casuística a partir da rede de relações de três pesquisadoras qualificadas para o trabalho. Foram utilizados dois instrumentos de entrevistas: um formulário semi-estruturado, para a caracterização socioeconômica e demográfica das mulheres e um roteiro temático, para a entrevista em profundidade. As entrevistas foram transcritas e organizadas no programa Ethnograph, utilizado em análises qualitativas de dados. 0 trabalho de campo durou cerca de seis meses. A seguir, o material coletado foi organizado em categorias empíricas, que deram origem a categorias gerais e a núcleos estruturadores do discurso.

\section{Resultados e Discussão}

\section{Mulheres brancas e concepções de liberdade}

Com relação à liberdade, mulheres brancas, de escolaridade fundamental, consideram que as mulheres conquistaram uma falsa liberdade, hoje em dia. Com isso apontam para a existência de uma visão essencialista da "mulher", na sociedade. Elas podem trabalhar, prover a casa e a família, mas não obtiveram a liberdade almejada. A liberdade está limitada à necessidade de cuidado dos filhos e aos cuidados domésticos. A "mulher" será sempre mulher, no sentido vitimizante do termo.

Uma falsa liberdade. A não ser que ela seja totalmente independente, mas se ela é casada, que nem no meu caso..... Está ali do lado do marido, é uma liberdade entre aspas. Não é totalmente liberdade, não. Cê fica presa a muitas coisas, a filho, casa, marido e essas coisas (Mary, mulher branca, ensino fundamental, não está usando nenhum método contraceptivo).

Mulher branca, de ensino médio, pensa nas próprias armadilhas que o jogo das relações de gênero impõe. Entende que a liberdade é uma quimera, que não foi alcançada pelas mulheres, que têm suas potencialidades “ceifadas". Desse ponto de vista, a sociedade coloca obstáculos para a mulher.

Ela trabalha, cuida de casa, cuida de marido, cuida de filho, é amante, muitas vezes ainda estuda, qual a hora de liberdade dela? De se expressar de que faz tudo isso, chega na hora de ela querer ter uma liberdade 
mesmo, de bater o martelo, muitas vezes ela é ceifada (Amália, mulher branca, ensino médio, marido vasectomizado).

As mulheres brancas, de nível médio, questionam essa liberdade. "Será que mudou mesmo?"; "Será que não estamos confundindo ainda mais as coisas?”. Esse sentimento de liberdade surge quando perguntamos sobre a liberdade da mulher, hoje em dia. De onde vem esse sentimento?

É possível perceber que as mulheres brancas se colocam no meio de um caminho, em meio a um processo histórico. A conclusão de algumas é que a mulher não tem liberdade, para além das obrigações do lar.

A mulher, hoje, ela tem liberdade p'ra tudo, ela tem direitos, ela tem o direito e o dever de prover, de dar à luz, de ser mulher, de ser amante, de ser esposa, mas a liberdade de, algumas vezes, ela fazer algumas coisas que ela gostaria de fazer ela não o faz, porque a sociedade não admite [Que tipo de coisas?] Ah, falar besteira numa roda de homens, estar num lugar onde só tem homens, as outras pessoas vão falar "Nossa, uma mulher casada, com filho num lugar que só tem homens", se tem muitos amigos gays, é porque ela tem tendência a também ser gay (Amália, mulher branca, ensino médio, marido vasectomizado).

Nesse sentido, a forma como se dá a conjugalidade não permitiria às mulheres desenvolverem a sua individualidade e, por conseguinte, a sua liberdade. Deste ponto de vista, o foco é a dinâmica das relações de gênero e, mais especificamente, nas relações conjugais. Em relação mais ao parceiro, às relações... Eu acho que na verdade não existe [a liberdade], por exemplo, no que se refere ao parceiro, que ela, que ela não... de uma maneira global, que eu convivo num meio, onde as mulheres que conheço elas não se encaixam no todo neste perfil, mas a maioria, pelo que eu percebo, as mulheres, elas têm muito receio de discutir a relação, de rever a postura de cada um dentro desta relação $e$ fazer essa divisão. E não é só um receio, porque o parceiro não dá esse espaço, eu entendo que o espaço é conquistado. Porque não dar o espaço e ficar calada, é consentir com essa ausência de espaço. Então, eu acho que a mulher, em nome de muitas coisas, perde essa liberdade que ela poderia ter, esse dividir. Em nome do quê? De manter uma relação, por exemplo, talvez o risco que ela imagina ter que, talvez não tenha, ou talvez tenha e talvez ela queira manter uma relação que talvez nem exista de fato, por que o que é relacionar? É dividir, eu imagino, eu penso dessa maneira, mas ela tem já uma carga que vem da criação, ou seja, que vem da mãe dela, da avó dela e que ela ainda não reformulou, ainda está na forma só, falta o conteúdo (Joana, mulher branca, ensino médio, camisinha masculina).

As mulheres brancas vêem, de modo geral, que sua liberdade pode ser ampliada. Para as de nível superior, a visão é a de que o trabalho é uma forma de exercício da independência feminina e de liberdade; esta visão, que é corroborada pelos parceiros, vai ao encontro do que Lipovetski (200o) assevera para a "terceira mulher": o direito de escolha. A liberdade, em seu sentido amplo, ainda está por ser conquistada, mas já é vislumbrada por algumas delas como, por exemplo, no caso da independência econômica; no direito de ir e vir, na liberdade de expressão dos desejos e outras conquistas. IVocê acha que a mulher hoje ela tem maior liberdade, do que há alguns anos atrás? Isso mudou, não mudou?] Por exemplo, eu acho que ainda... as mulheres avançaram muito em independência econômica, e eu vou estar falando no meu caso específico, porque eu falar de todas as mulheres, de gênero, eu acabo não vendo e resgatando a minha própria experiência que é, de liberdade, eu não tenho a menor dúvida. Eu sou de uma geração que conquistou liberdades importantes, eu tenho independência econômica, e isso é fundamental para discutir liberdade, não é? Porque isso me garante fazer algumas coisas que antes não eram garantidas. Eu acho que as mulheres de hoje, as opiniões, elas têm opiniões, falam dessas opiniões, têm a liberdade de poder falar, a liberdade de poder sair, a liberdade de poder sentir, várias liberdades nós já conquistamos, acho ainda que tem muito a avançar, muito a avançar, que é a liberdade de decidir, sobre o poder. Ter poder social, ter poder político, ter poder econômico igual. Eu acho que nós não conquistamos plenamente, mas a trajetória feminina é uma trajetória de conquistas de liberdade (Solimar, mulher branca, ensino superior, camisinha masculina).

Enquanto mulheres brancas, de nível médio e fundamental, apontam uma situação de maior heteronomia, mulheres brancas de nível superior podem, por meio de uma inserção mais efetiva na sociedade e, mais especificamente, no mercado de trabalho, conquistar uma maior autonomia e liberdade. 


\section{Mulheres Negras e as Concepções de Liberdade}

Em seus discursos, mulheres negras, de escolaridade de nível fundamental, percebem dificuldades no exercício da sua liberdade, mas desafiam esses obstáculos, impondo sua presença e hábitos, antes questionados como femininos. A dinâmica da relação conjugal é, forçosamente, flexibilizada para permitir a liberdade feminina. Observa-se, no discurso a seguir, que o quê se quer conquistar é o espaço público, figurado no discurso de Pámela, como espaço também de lazer, além do trabalho. Diferente da mulher branca, ela apresenta um discurso menos preso às convenções do papel feminino e masculino.

Às vezes, em que situação, assim, quando eu saio do serviço e fico assim, fico no barzinho com as colegas. Não é barzinho, assim...que tem do lado do serviço, que a gente bebe uma, duas, três cervejas. Assim, no último plantão, antes de vir embora. Ai eu não ligo, não dou ouvido (risos). Porque se ele pode fazer com os amigos, por que eu não posso fazer com as minhas amigas? Claro. Aí, eu faço do mesmo jeito (Pámela, mulher negra, ensino fundamental, laqueada).

Segundo Eliane, a possibilidade de exercício da liberdade do direito de ir e vir é limitada pelo companheiro. O lugar do lazer é o lugar convencionalmente ligado à paquera, também de acesso a outros homens (Souzas e Alvarenga, 2001). É interessante observar que Eliane afirma que a mulher tem o direito de trabalhar fora, mas não de lazer, sem a companhia do marido, o que é reivindicado por Pámela, interlocutora anterior.

Ele não aceita toda essa liberdade, não. Ele acha que a mulher tem direito de trabalhar fora, de ter igualdade com o homem, mas, por exemplo, a liberdade da mulher querer ser livre, querer sair de casa, por exemplo, para passear, sem ele estar junto, sair com amiga, fazer todas essas coisas, ele não concorda não (Eliane, mulher negra, ensino fundamental, laqueadura associada à camisinha).

Diferentemente da mulher branca, de nível médio, que reivindica uma liberdade equiparada à do homem, a mulher negra, de igual escolaridade, reivindica um tipo de liberdade atualizada, não equivalente à do homem, mas que vai além do que era permitido antigamente, quando a mulher era mais subserviente ao homem na relação conjugal.
[E o que você acha da maior liberdade que as mulheres têm hoje?] Muito bom, ótimo, porque antigamente a gente não tinha, não é?, este tipo de liberdade. Eu tiro pela minha mãe, muitas coisas ela queria fazer $e$ não fazia... Hoje, não... hoje nós temos, não é?, várias coisas, tipo: se a gente quer trabalhar fora... Já é um grande passo pra mulher. [Quando você fala assim "ah, no tempo da minha mãe era diferente". Em que sentido, mais ou menos, você acha que era diferente?] Tá. Por exemplo, trabalhar fora. Hoje nós podemos. Se a gente falar assim "quero trabalhar fora"..é lógico que existe ainda muitos homens que não deixam, mas na época da minha mãe, não podia mesmo. Você tinha que obedecer ao homem, tinha que ser...não respeito, era obediência mesmo. Hoje não, hoje você tem respeito pelo teu marido, você não tem medo do teu marido. Pelo menos é o meu caso (Marina, mulher negra, ensino médio, não está usando nenhum método contraceptivo).

Algumas das mulheres negras entrevistadas, de nível fundamental e médio, reivindicam liberdade para seu cotidiano. Hortênsia menciona, também, que essa liberdade tem um preço: "arcar com as conseqüências", associadas à possibilidade de decidir sobre a sua própria vida e destino. As mulheres identificadas como de "classe média", para Hortência, são as que ficam presas a conceitos e a convenções e que, portanto, não exerceriam a liberdade.

[O que acha da liberdade da mulher hoje em dia?] Eu acho muito positivo, muito positivo. [Em que aspecto é positivo?] Ah, porque antes você ficava muito presa a conceitos, a família e hoje não. Você pode batalhar pelo seu próprio espaço. Você pode... tem o direito de ir e vir a hora que quiser sem pedir satisfação. Se bem que algumas ainda ficam presas. [Algumas? Que mulheres ficam presas?] Ah, eu vejo as da classe média principalmente. [As da classe média?] As da classe média principalmente. Tem que pedir autorização para marido ir nos lugares. Não tem nada a ver. Acho que todo mundo é livre para fazer o que quiser. Acho que nesse ponto que é a liberdade. Você pode fazer o que você quiser, aí você arque com as conseqüencias. (Hortênsia, mulher negra, ensino superior, laqueada).

Em seus discursos, as mulheres negras, de ensino superior, percebem o alcance das conquistas femininas no cotidiano, vivem essa liberdade e a concebem como uma possibilidade de poder expressar-se sem constrangimento, com liberdade de pensamento. A 
questão da liberdade, entretanto, exclui as experiências sexuais, para além do relacionamento conjugal. É a idéia da monogamia absoluta, como elemento constitutivo da conjugalidade das mulheres, como é apontada pela interlocutora Luísa. Para ela, a liberdade é abdicar dessa possibilidade sexual, é "não ter uma relação conjugal e uma relação extraconjugal”, é ter relação monogâmica, compartilhada, como uma construção efetiva na vida de mulheres negras.

Tem que ver o que é liberdade. Liberdade pra mim, dentro de um relacionamento, é você poder ter o seu pensamento, as suas idéias, você ser respeitado, é uma coisa, e outra coisa, eu não sei se as pessoas colocam isso, o conceito de liberdade é você poder partilhar as coisas com seu parceiro. Ele poder partilhar com você. Você poder sentar dialogar, conversar de tudo. Entendeu. Até de uma simples coisa. "Ah eu vou fazer isso hoje, eu vou fazer aquilo", aceitação. Acho que isso é uma questão de liberdade. Eu não chamo de liberdade, aquilo de você ter uma relação com liberdade. É não ter uma relação conjugal e uma relação extraconjugal. Compreendeu? Porque isso aí, eu não sei se isso éliberdade. Isso é opção. Você optar por viver assim. Ah agora em relação eu produzir, ter a minha vida, trabalhar, ganhar o meu dinheiro. Isso é muito tranqüilo no meu relacionamento. Isso eu chamo de liberdade. Não esse outro lado que eu te falei (Luisa, mulher negra, ensino superior, camisinha masculina).

A liberdade de compartilhar, dividir, ainda é uma quimera para muitas mulheres. Pinto (2002), ao analisar a questão do aborto, aponta a solidão em que vivem, principalmente, as mulheres negras, no processo de decisão pelo abortamento. Percebe que os informantes brancos incorporaram os mitos com relação à sexualidade negra e vêem as mulheres negras como objeto sexual, ao passo que informantes negros incorporaram o ideal de brancura, com todo o poder que ela representa, preferindo filhos miscigenados, embora os brancos não vissem as mulheres negras como mãe para seus filhos.

Com isso, observa-se que a decisão reprodutiva está enredada em formas de poder nas relações sociais. Nesse contexto, a liberdade, segundo Chauí (1985, p. 36), "não é, pois, a escolha voluntária em face de várias opções, mas a capacidade de autodeterminação para pensar, querer, sentir e agir. É autonomia”. Liberdade é, ainda, a capacidade que temos para transformar uma realidade, por exemplo, de exclusão, e construir uma relação igualitária.

Podemos pensar que mulheres negras e brancas, de escolaridades diferenciadas, vivem em maior ou menor heteronomia ou autonomia moral, partindo do pressuposto de que os sujeitos sociais e políticos - mulheres negras e brancas - estão em patamares distintos da trajetória em direção à autonomia moral, se avaliarmos a partir do modelo proposto por Venturi (2003). Souzas e Alvarenga (2001) observaram que, entre mulheres de baixa renda, o discurso de liberdade refere-se ao direito de ir e vir, limitado pela atuação dos maridos, que obstaculizam a sua ação. Em ações requerem a capacidade de decisão e escolha e a participação dos parceiros, como no planejamento familiar, por exemplo, as mulheres vêem-se impedidas por uma relação de gênero rígida, ficando visível a ausência de diálogo entre homens e mulheres. É nesse sentido que procuramos buscar compreender, por meio do discurso de mulheres brancas e negras entrevistadas, as concepções sobre liberdade.

0 grau de liberdade de que a mulher usufrui determina sua autonomia. Segundo Miller (2003), os direitos sexuais estão ligados à autonomia e à dignidade humana e não a uma identidade sexual. A autora aponta como um aspecto radical das demandas pelos direitos sexuais o enfrentamento de esteriótipos sexuais, que se dá com a participação das pessoas mais atingidas e mais marginalizadas. É interessante, neste ponto, pensar que, no Brasil, mulheres negras são preteridas do mercado matrimonial, como aponta Berquó ${ }^{2}$ e supervalorizadas, como exóticas, para o tráfico sexual, como denunciam pensadoras do movimento negro. 0 esteriótipo a que as mulheres negras estão submetidas impede-as de usufruírem da liberdade, inclusive a sexual, e de exercitarem sua autonomia e dignidade, ferindo, portanto, os direitos sexuais das mulheres negras.

Mulheres brancas apontam para uma ilusória liberdade: o "feitiço contra o feiticeiro", como se a busca pela igualdade ou pela afirmação da diferença as tives-

2 BERQUÓ, E. Estudo da dinâmica populacional do negro no Brasil. Campinas, 1986. Texto Nepo 9. 
se colocado numa "cilada" (Pierucci 20oo). Ao terem sua diferença afirmada para contestar um tratamento desigual, tiveram a sua condição diferenciada, justificada na própria diferença, colocada por elas mesmas.

As visões de mulheres brancas e negras diferem com relação à idéia de liberdade e apontando uma vivência distinta. Enquanto o grupo de mulheres brancas indica uma falsa liberdade das mulheres, que continuam subordinadas de diferentes formas à relação conjugal, o grupo de mulheres negras entende a liberdade como o poder de se expressar no diálogo com o parceiro, ou seja, a possibilidade de vivência democrática da conjugalidade. Essas diferentes formas de conceber a liberdade sinalizam diferentes compreensões da sua condição de gênero e raça. Enquanto mulheres brancas problematizam essa condição e a possibilidade de exercício efetivo da liberdade, mulheres negras apontam a conjugalidade, na realidade atual, e o avanço da possibilidade de diálogo.

Entendemos que essa compreensão diferenciada de liberdade se dá em função das diferentes condições, de gênero, de raça e de condição social das mulheres. Esses três elementos articulados dão a essas mulheres uma possibilidade de vivência sexual e afetiva diferenciada. Enquanto mulheres brancas buscam superar certa dicotomia na relação, mulheres negras buscam construir uma relação conjugal que, ao longo do tempo, foi dificultada, em parte, pela condição histórica de escravidão. Segundo Bernardo (1998), a família negra, formada, inicialmente, por mãe e filho, com o advento da Lei do Ventre Livre, excluía o homem negro, pela sua própria condição. Mulheres negras, portanto, ocupavam um lugar central na formação dessa família. Beozzo (1993) destaca a fragilidade das famílias escravas e como a igreja cumpriu um papel importante na intervenção junto aos senhores de escravos para a manutenção desse tipo de família. As escravas, quando engravidavam, muitas vezes, praticavam o aborto para que o filho não sofresse a mesma sina. A legislação da época apoiava fracamente esse tipo de organização social e, muitas vezes, como foi o caso da lei dos sexagenários, surgia para proteger os senhores de qualquer tipo de obrigação com a escravaria.

A idéia de parceria no relacionamento conjugal é uma idéia nova e faz parte das conquistas femininas
(Giddens, 1993). A vivência da conjugalidade, no sentido moderno do termo, como uma experiência de compartilhamento é, então, uma novidade na vida das mulheres negras. Agrega-se a isso a constatação de Berquó ${ }^{3}$ que, ao analisar a nupcialidade da população negra, identificou uma maior solidão das mulheres. Esse dado agrega mais valor à conjugalidade. Percebese, então, nessa questão, uma diferença étnico-racial.

\section{Conclusões}

Para Bobbio (1997), a liberdade positiva diz respeito ao exercício de uma vontade autodeterminada e não heterodeterminada; é uma liberdade que diz respeito ao cidadão, porque ele consentiu as leis que regulam a sua ação. É uma liberdade de sujeitos autônomos, autodeterminados. Assim, a relação de gênero igualitária, a que se refere Giddens (1993), pressupõe o exercício da liberdade.

Sem serem antagônicas, as concepções de liberdade de mulheres negras e brancas possibilitam identificar a visão de algo a ser superado pelas mulheres. As diversas visões de liberdade permitem perceber que os dois segmentos, o de mulheres brancas e o de mulheres negras, direcionam suas reflexões para a constatação de que houve uma mudança no mundo das mulheres. Enquanto as brancas pensam na defasagem das mulheres, no exercício eqüitativo da liberdade em relação aos homens, as negras pensam na possibilidade de vivência democrática da conjugalidade. Essas diferentes concepções são especialmente relevantes para se pensarem as escolhas reprodutivas de mulheres negras e brancas e desvelar uma condição feminina diferenciada por cor.

Enquanto mulheres brancas partem de uma visão de que "mulher é sempre mulher" (ensino fundamental), para atingir uma visão de conquista de maior autonomia (nível superior), mulheres negras (ensino fundamental) partem de uma visão de pouca liberdade, expressa na dificuldade de ir e vir e no desejo de ampliar o espaço da rua como espaço de lazer, além de trabalho, para uma visão de liberdade na conjugalidade (nível superior). Essa situação é diferente no caso da mulher branca, que aponta para conquistas no mercado de trabalho e de outros espaços. Enquan-

3 BERQUÓ, E. Nupcialidade da população negra no Brasil. Campinas, 1987. Texto Nepo 11. 
to mulheres brancas visam à vida pública, mulheres negras visam à vida privada. Considerando as diferentes histórias de mulheres negras e brancas e constatando que mulheres negras têm uma história de vida pública, inscrita em trabalhos forçados e desqualificados, podemos considerar que elas partem para organizar sua vida privada como tarefa histórica.

Se considerarmos, como Scott (1991), que a primeira instância de articulação do poder é a relação de gênero, podemos pensar que a mulher negra - que, historicamente, sofreu a tripla discriminação (raça, classe, sexo) - está problematizando essa primeira instância. Dessa perspectiva, sinaliza uma condição e um exercício diferenciado da liberdade. Apresenta como essa vivência é marcada pela discriminação. Essa mesma mulher negra, também, está organizada e politiza suas questões, buscando construir uma história diferente, em que o direito de decidir pelo seu corpo, uma bandeira feminista, passa pela mudança dos padrões de relações de gênero, historicamente, diferentes entre brancas e negras.

\section{Referências}

BEOZZO, J. O. A família escrava e imigrante na transição do trabalho escravo para o livre. In: MARCILIO, M. L. (Org.). Família, mulher, sexualidade e igreja na historia do Brasil. São Paulo: Loyola, 1993. p. 29-99

BERNARDO T. Memória em branco e negro: olhares sobre São Paulo. São Paulo: EDUC: Unesp, 1998.

BOBBIO, N. Igualdade e liberdade. Rio de Janeiro: Ediouro, 1997.

CHAUÍ, M. Participando do debate sobre mulher e violência. In: CHAUÍ, M.; CARDOSO, R.; PAOLI, M. C. (Org.). Perspectivas antropológicas da mulher: sobre mulher e violência. Rio de Janeiro: Zahar, 1985. v. 4, p. 25-62.

GIDDENS, A. As conseqüências da modernidade. São Paulo: Unesp, 1991.

GIDDENS, A. A transformação da intimidade: sexualidade, amor \& erotismo nas sociedades modernas. São Paulo: Unesp, 1993.
LIPOVESTSKY, G. A terceira mulher: permanências e revolução do feminino. São Paulo: Cia das Letras, 2000 .

MILLER, A. Os direitos sexuais: avanços conceituais e debate. In: SEMINÁRIO REGIONAL SOBRE DIREITOS SEXUAIS, DIREITOS REPRODUTIVOS, DIREITOS HUMANOS, 3., 2003, Lima. Anais... São Paulo: CLADEM, 2003. p. 121-140.

OLIVEIRA, R. D. de. O elogio da diferença: o feminino emergente. São Paulo: Brasiliense, 1991.

PATEMAN, C. O contrato sexual. Rio de Janeiro: Paz e Terra, 1993.

PIERUCCI, A. F. Ciladas da diferença. São Paulo: Ed. 34, 2000.

PINTO, E. Ventres livres: o aborto numa perspectiva étnica e de gênero. São Paulo: FalaPreta!: Terceira Margem, 2002.

RODRIGUES, N. Educação: da formação humana à construção do sujeito ético. Educação \& Sociedade, São Paulo, ano XXII, n. 76, p. 232-257, 2001.

SCOTT, J. Gênero: uma categoria útil para a análise histórica. Recife: SOS-Corpo, 1991.

SOUZAS, R. Relações raça e gênero em jogo: questão reprodutiva de mulheres negras e brancas. 2004. Tese (Doutorado em Saúde Pública) - Faculdade de Saúde Pública da USP, São Paulo, 2004.

SOUZAS, R.; ALVARENGA, A. T. Da negociação às estratégias: relações conjugais e de gênero no discurso de mulheres de baixa renda em São Paulo. Saúde e Sociedade, São Paulo, v. 10. n. 1, p. 15-34, 2001.

TELLES, V. da S. Direitos sociais: afinal do que se trata? Belo Horizonte: UFMG, 1999.

VENTURI JR, G. Democracia e autonomia moral: universalismo moral e relativismo ético em teorias normativas da democracia. 2003. Tese (Doutorado em Ciência Política) - Faculdade de Filosofia, Letras e Ciências Humanas da USP, São Paulo, 2003. 